\title{
A Seven-week Module to Introduce Electrical and Computer Engineering to Freshmen Engineering Students
}

\section{Dr. Kala Meah, York College of Pennsylvania}

Kala Meah received the B.Sc. degree from Bangladesh University of Engineering and Technology in 1998, the M.Sc. degree from South Dakota State University in 2003, and the Ph.D. degree from the University of Wyoming in 2007, all in Electrical Engineering. From 1998 to 2000, he worked for several power companies in Bangladesh. Currently, Dr. Meah is an Associate Professor in the Electrical and Computer Engineering program, Department of Engineering and Computer Science, York College of Pennsylvania, York, PA, USA. His research interest includes electrical power, HVDC transmission, renewable energy applications, energy conversion, and engineering education.

\section{Dr. James Moscola, York College of Pennsylvania}

James Moscola is an Associate Professor of Computer Science and Computer Engineering at York College of Pennsylvania. He received a B.S. in Physical Science from Muhlenberg College in 2000, a B.S. in Computer Engineering, a M.S. in Computer Science, and a Ph.D. in Computer Engineering from Washington University in St. Louis in 2001, 2003, and 2008 respectively. His interests include reconfigurable architectures and embedded systems.

\section{Dr. James A. Kearns, York College of Pennsylvania}

Jim Kearns is an Associate Professor of Electrical \& Computer Engineering at York College of Pennsylvania. He received a B.S. in Mechanical Engineering (SEAS) and a B.S. in Economics (Wharton) from the University of Pennsylvania in 1982. Subsequently, he received his M.E. from Carnegie-Mellon University in 1984, and his Ph.D. from the Georgia Institute of Technology in 1990, both in Mechanical Engineering. While at Georgia Tech he was the recipient of a Presidential Fellowship. Subsequently, he worked as a Postdoctoral Fellow at the Applied Research Laboratory of the University of Texas-Austin. Dr. Kearns has spent the past 22 years at York College of Pennsylvania developing new programs in mechanical, electrical, and computer engineering. In 2016 he co-authored the 6th edition of Principles and Applications of Electrical Engineering with Dr. Giorgio Rizzoni of the Ohio State University.

\section{Dr. Eleanor Leung, York College of Pennsylvania}

Dr. Eleanor Leung is an assistant professor with the Electrical and Computer Engineering program of York College of Pennsylvania. Her research area is in wireless communications focusing on space-time block coding and the design of signal constellations. Her technical research area is in wireless communications focusing on space-time block coding and the design of signal constellations. She is also doing research work focused on active and collaborative learning in engineering education. Eleanor has a B.S in Electrical Engineering from the University of Calgary and both a M.Eng and a Ph.D in Electrical Engineering from McMaster University.

\section{Dr. Jason Forsyth, James Madison University}

Jason Forsyth is an Assistant Professor of Engineering at James Madison University. He received his PhD from Virginia Tech in May 2015. His major research interests are in wearable/ubiquitous computing and engineering education.

His wearable computing work develops safety systems that provide continuous monitoring and sensing to protect human life. Previous work examined the role of wearable pulse oximetry in protecting construction workers from carbon monoxide poisoning and developing a warning system for road-side workers and emergency personnel to estimate potential vehicle strikes. His current research interests focus on on-body human activity recognition and interactive machine learning for physical therapy patients and practitioners to increase exercise adherence and clinical evaluation. 


\title{
A Seven-week Module to Introduce Electrical and Computer Engineering to Freshmen Engineering Students
}

\begin{abstract}
This complete evidence-based practice paper details a seven-week module used to introduce first-semester engineering students to the fields of electrical and computer engineering. The module engages the students in a guided design process using a custom robotic platform, the Ebot, that students incrementally build and enhance each week. Initially, students build an Ebot that they can manually drive forward and backward. By the end of the module, students create an autonomous line following robot. Throughout the process, students are asked to reflect upon how they could improve upon the previous week's design. As part of this process students are introduced to various electrical/electronic devices, such as a digital multimeter, a DC power supply, SPST and SPDT switches, a phototransistor, DC motors and a microcontroller. However, the primary goals of the module are to introduce students to aspects of electrical and computer engineering and engineering methodology related to design, and to establish a sense of affiliation and connection between the students, the faculty and the engineering school.

Enrollment in each module is capped at 18 students so that each student can receive significant individual attention and support from the faculty. Each faculty member actively fosters supportive relationships with and between the students and encourages self-confidence through the guided team-based activities. At the conclusion of the most recent offering, students were surveyed. The majority of students surveyed viewed the ECE module favorably: 89\% agreed that they had learned a great deal in the ECE module; $78 \%$ agreed that the module provided them with an understanding of the electric and computer engineering fields; $91 \%$ agreed that the module was fun. The course addresses ABET student outcomes 2, 3, and 5. These outcomes focus on engineering design, communication, and teamwork, respectively.
\end{abstract}

\section{Introduction}

Traditional first-semester engineering curriculum includes basic mathematics, sciences, and liberal arts courses in order to prepare students for rigorous engineering courses. This approach helps highly motivated students who have clear understanding of their field of study. Most high school graduates may have an understanding of the overall engineering field but may not know about a specific field of engineering. A hands-on introduction to each engineering field is necessary in the early stage of the curriculum and the first semester is an ideal place to expose students to various engineering fields and help them to make an informed decision about their future career. To facilitate this idea, engineering programs at York College of Pennsylvania offer a 
common first semester, where all engineering students (and some undeclared students curious about engineering) take a design-based engineering course, Engineering Practices and Design Studio (EPADS), along with other common courses. This design course consists of two modules: an Electrical and Computer Engineering (ECE) module; and a Mechanical and Civil Engineering (MCE) module. Students spend seven weeks working on each module, exploring basic concepts in each discipline. In the MCE module, students work with Computer Aided Design (CAD) tools, basic hand tools, and machine tools in a machine shop. In the ECE module, students develop basic skills working with electrical/electronic devices, sensors, actuators, and programming. The seven-week ECE module is divided into the following units: introduction to electrical terminologies, basic electrical test equipment, testing, and plotting motor data; switches, crimping, and soldering; operational amplifiers and potentiometers; Arduino microcontrollers and basic programming; gate drivers, infrared sensors, and autonomous navigation. To explore these topics, the ECE module utilizes a custom robotic platform, called the Ebot. This platform is equipped with dual onboard power supplies, motors, and a small breadboard. Students use the Ebot platform to build and test a variety of electrical circuits throughout the different units.

This introductory design course emphasizes the following:

- exposing freshmen engineering students to all available engineering fields at York College of Pennsylvania using modules so each can make an informed decision about their future career;

- familiarizing freshman engineering students with what it means to be an engineer and how engineers think;

- developing a sense of teamwork and building student confidence;

- exposing students to the creative art of design early in the engineering curriculum;

- developing basic skills in the use of computers, electronic devices, sensors, CAD, hand tools, and machine tools;

- retaining students who possess the interest and ability to succeed in engineering by providing interesting design projects and fun competitions;

- improving the oral and pictorial communication skills of students.

\section{Literature Review}

ABET criteria for accrediting engineering program requires "a culminating major engineering design experience that 1) incorporates appropriate engineering standards and multiple constraints, and 2) is based on the knowledge and skills acquired in earlier course work." ABET student outcomes place an emphasis on teamwork and effective communication [1]. An early introduction to these requirements is achieved through this course, as it is a designed-based course for all engineering students in which they work in a team. Project-based curriculum and active learning techniques have been increasingly becoming the common intervention to create excitement and to improve student satisfaction and perception in engineering programs across the nation $[2,3,4,5]$. Engineering Curriculum at the University of Nevada, Reno includes two freshmen courses. The first is a combined mechanical, electrical and civil engineering course in 
which students work on interdisciplinary teams building digital scales. The second course is for mechanical engineering, material science engineering, and computer science students and focuses on structured programming through the use of robotics [6]. Prendergast and Etkina introduced students to different engineering majors using semi-structured project-based collaborative learning techniques. They reported that the increased engagement resulted in higher student satisfaction and increased retention [7]. Grand Valley State University engineering curriculum offers a freshmen design course that covers 3D solid modeling design techniques and hands-on experiences in computer-numerically controlled (CNC) milling [8]. The freshmen engineering design course at York College of Pennsylvania is different from other courses in its category because it uses major specific modules to introduce specific engineering fields such as electrical and computer engineering, mechanical engineering, and civil engineering to all engineering students. School of Engineering at the University of Illinois at Urbana-Champaign developed a course entitled "Engineering Exploration" to increase engineering exposure, to improve retention, and make a connection between the first-year courses and engineering practices. This course provided an opportunity for students to see the dynamic nature of engineering fields along with basic mathematics and science courses. This paper reports that three-year retention increased by $19 \%$; and students reported higher satisfaction with their experiences compared to the students enrolled in a traditionally taught introduction to engineering course [9]. Rigorous introduction to an engineering field could be overwhelming and challenging for many students and may shy them away from the major. An early project-based course to introduce students to the tools (programming, electronics, lab equipment, CAD, machine shop) and to the breadth of the engineering profession is an effective practice. This type of course can build confidence in students and help them to succeed in this worthwhile endeavor [10]. The module-based introductory engineering course at York College of Pennsylvania not only serves the above purposes but also focuses on the faculty-student relationship. Full-time faculty primarily teach this course with no more than 20 students in the laboratory to engage students on a personal level. Personal connection and easy access to the faculty is an important element of students' success in academia and this course starts that process very early in the curriculum.

\section{Course Organization and Weekly Topics}

Engineering Practices and Design Studio (EPADS) is a two-credit laboratory based course. This course is available to all engineering students and any students who are interested in engineering. The class meets for two hours on Mondays, Wednesdays, and Fridays. The instructor has the option to make one of the three scheduled days a project day when students can meet as a team to plan project activities. The instructor is available to help students if necessary on the project day. The faculty from civil, computer, electrical and mechanical engineering programs co-teach this course. This course provides an opportunity for the engineering faculty to create the long lasting bond with the freshmen engineering students.

One-half of the semester students work with the faculty from mechanical and civil engineering programs and the other half of the semester they work with the faculty from electrical and computer engineering program. This paper focuses on the electrical and computer engineering (ECE) module of the EPADS course. A robotic platform (Ebot) is the central element of this module. Two students (regardless of their major) work as a team and each team has their own 


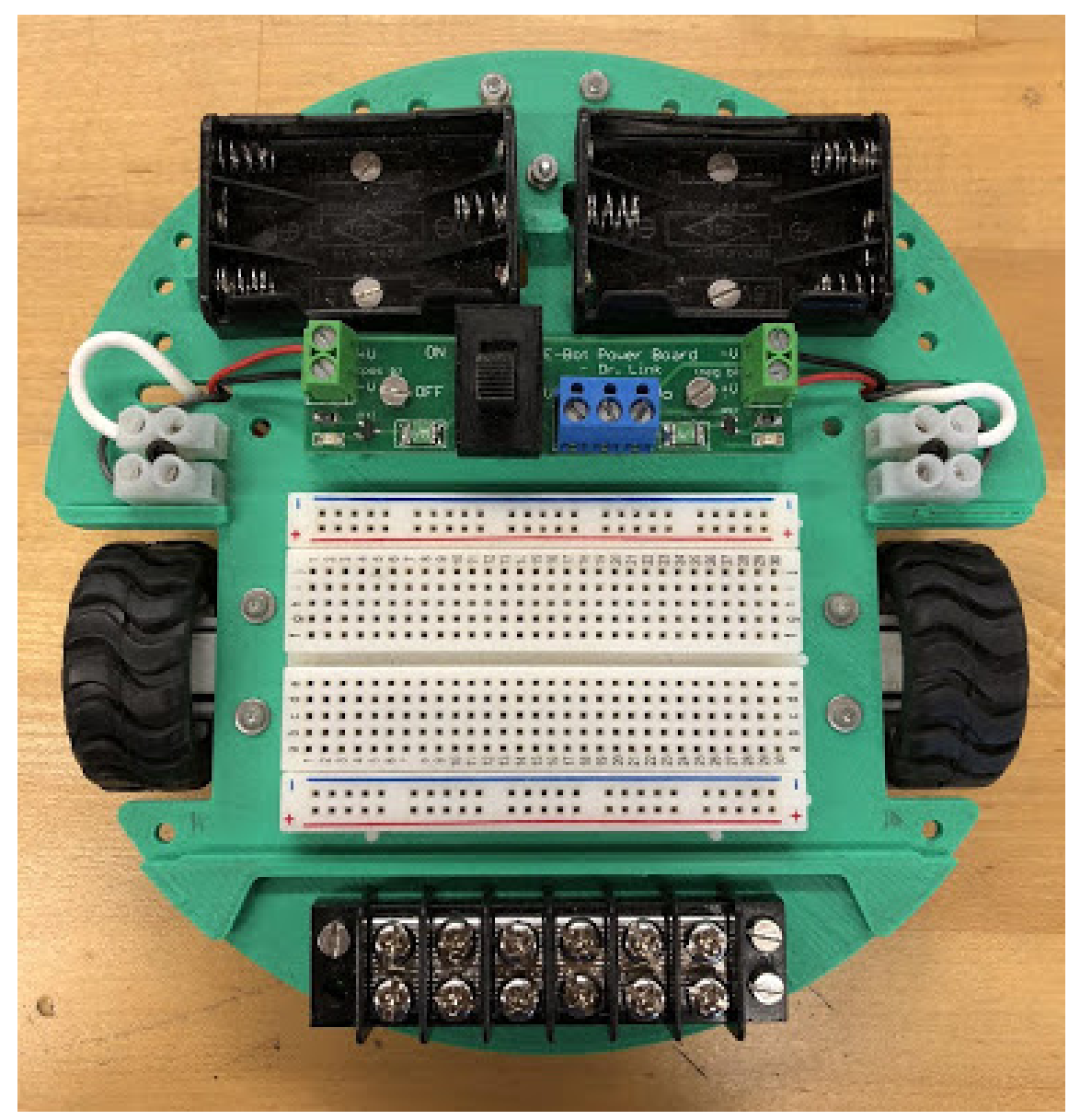

Figure 1: Ebot platform

Ebot. The Ebot consists of a power board, two DC motor powered wheels, a small breadboard, a terminal block, and two battery holders (AAA). Fig. 1 shows the Ebot platform. The grading of the ECE module emphasizes active learning and participation: quizzes: $40 \%$ of the grade; behavior and activities/participation: 60\% of the grade (Are you here? Participating?

Cooperating? Does your stuff work?). The robot competition cannot hurt the student's grade, but lack of participation can. A brief week-by-week activity schedule is provided below.

\section{Week 1}

During the first week, students are introduced to the electrical and computer engineering (ECE) module, grading criteria, digital multimeters, the Ebot, basic electrical terms, and Microsoft Excel. Students use digital multimeters to measure current through each motor with varying terminal voltages. The concepts of no-load current and stall current are introduced. Students use Microsoft Excel to produce two plots: motor current vs terminal voltage; and power vs voltage. Students also use trend lines and curve fitting on the plots. 


\section{Week 2}

Students learn about switching concepts such as SPST, SPDT, DPDT, NC, and NO. Basic soldering terminologies are introduced. Students practice soldering by connecting two wires to SPST switches. The goal for this week is to drive the Ebot with two SPST switches, a controller, and a tether wire. Fig. 2 shows the controller shell before it is populated with switches and potentiometers. Fig. 3 shows the circuit diagram for the second week. This 3D printed controller has slots for SPST switches, SPDT switches, rotational potentiometers, and slide potentiometers. It also has a terminal block on the back side to connect the tether wire.

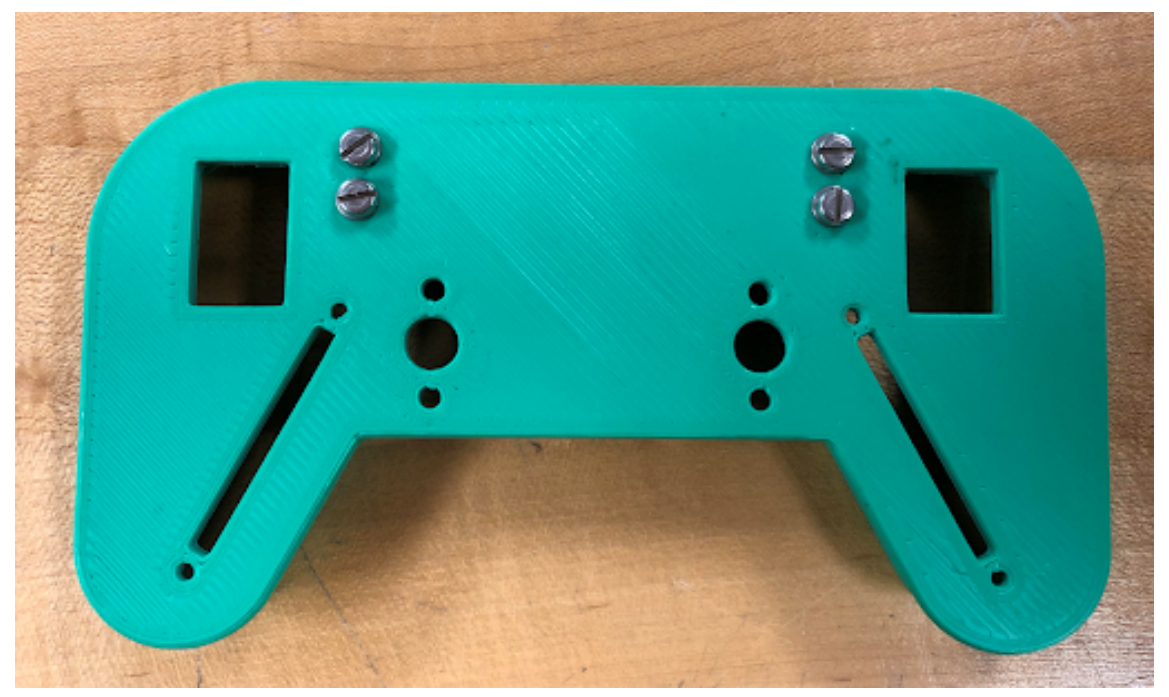

Figure 2: Ebot handheld controller shell

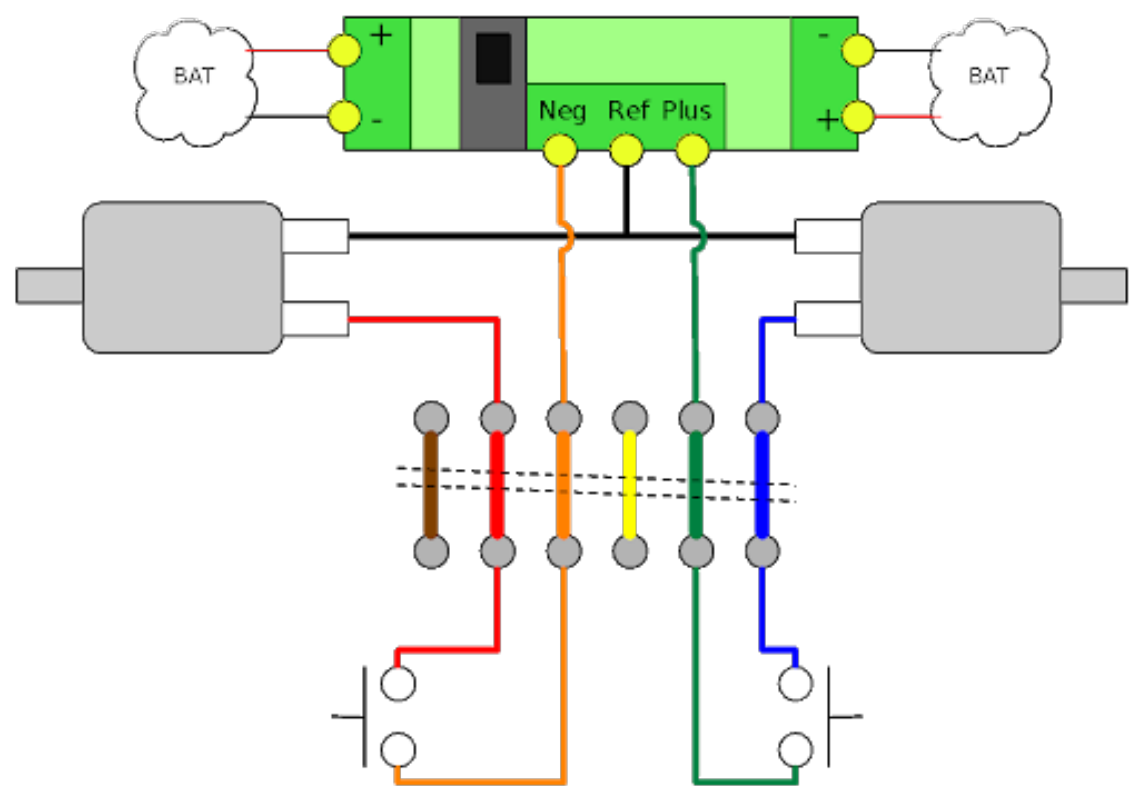

Figure 3: The SPST circuit diagram 


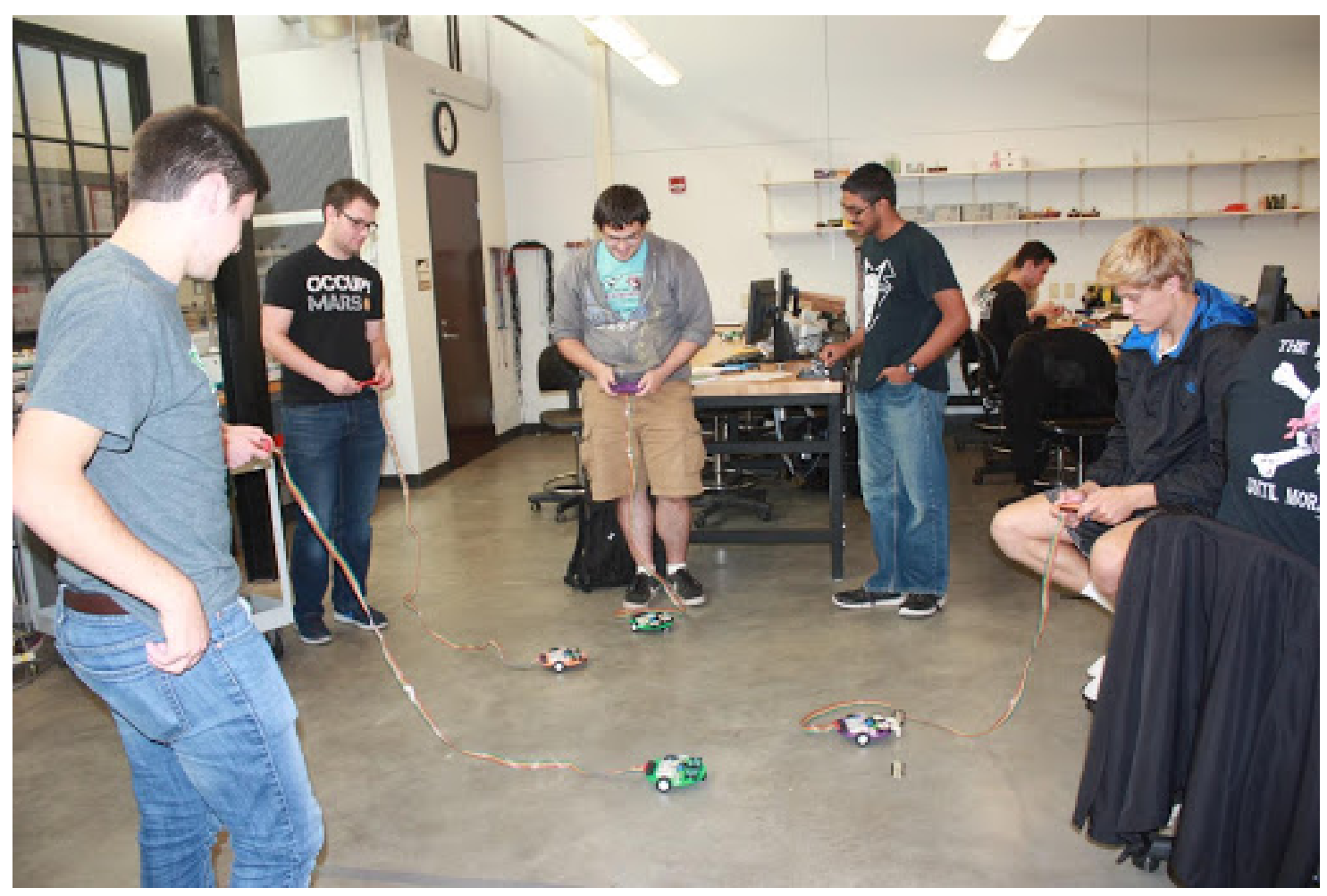

Figure 4: Students driving Ebots with the controller

\section{Week 3}

Students practice crimping and make two SPDT switches ready to connect the controller with the Ebot through the tether wire. The SPDT switch provides the capability to drive the Ebot forward and backward. The concept of an H-bridge is introduced. At the end of the week students drive their Ebots and follow a line on the floor. Fig. 4 shows students driving their Ebots using the SPDT switches on the controller.

\section{Week 4}

Students learn about operational amplifiers (Op-amp) and their application as a comparator. The floating voltage problem is examined at the inputs of the Op-amp comparator. The concept of pull-down resistor is introduced to solve this problem. At the end of the week the Op-amp comparator is breadboarded on the Ebot chassis and integrated with the SPDT circuit to reduce the current passed through the tether wire while maintaining the ability to drive the Ebot.

\section{Week 5}

The concept of a variable resistor is introduced as a tool to control the input voltage of the Op-amp comparator. Students replace the SPDT switches on the controller with variable resistors (rotational or slide potentiometers). The comparator circuit with variable resistors is shown in Fig. 5. At end of the week students have a fully functional Ebot on which they can control the speed and direction using the variable resistors. The tether is still connected to the Ebot. During 


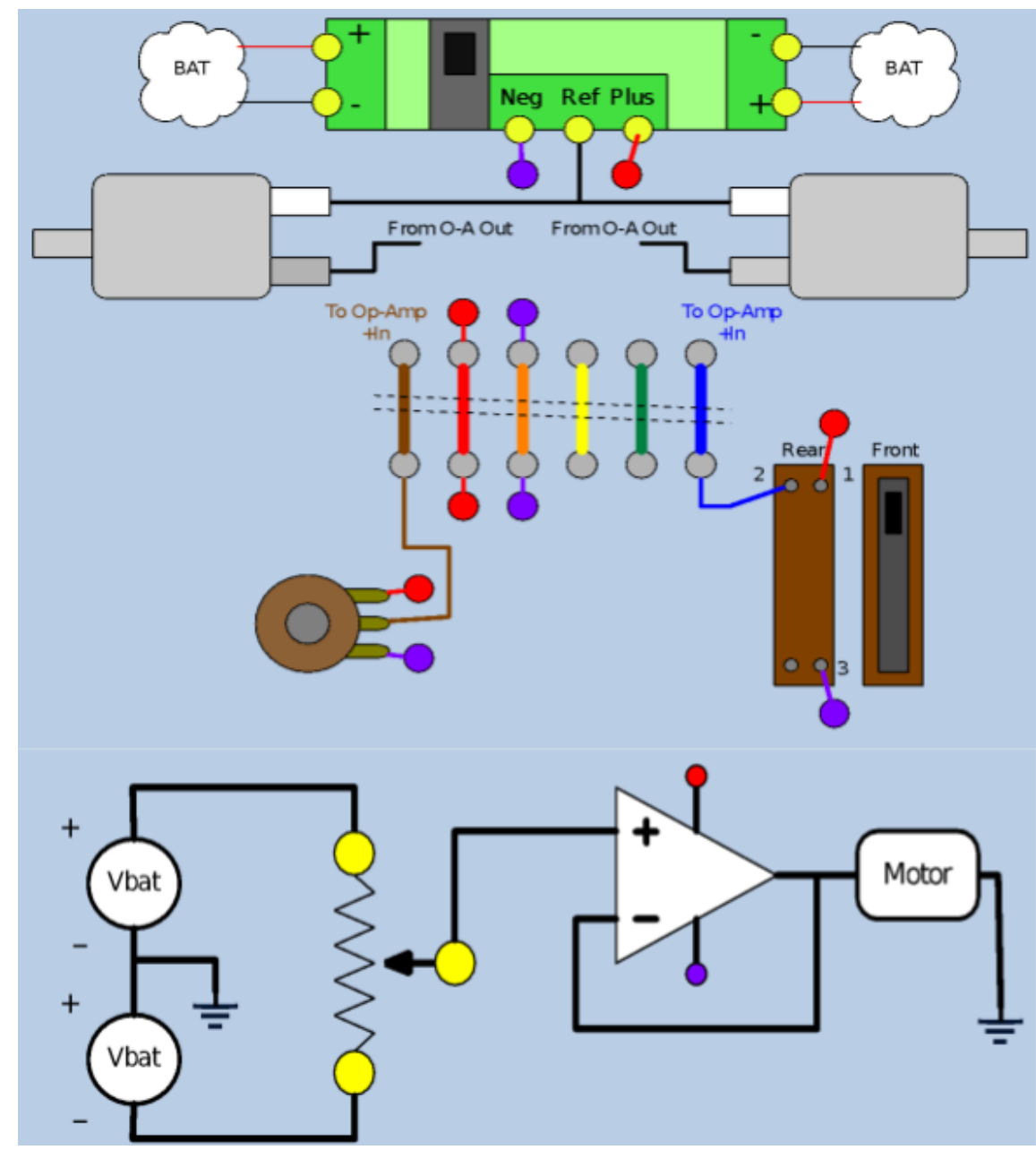

Figure 5: Incorporating a variable resistor with an Op-amp for Ebot control

next two weeks, students will integrate sensors, electronics, and programming to make the Ebot an autonomous line follower.

\section{Week 6}

Students learn about Arduino microcontrollers, basic programming, motor driver ICs, and infrared (IR) sensors. Students are provided step-by-step instructions on how to connect the motor driver (L293D) to the digital I/O of the Arduino microcontroller. The two Ebot motors are controlled using individual PWM signals generated by the microcontroller. Custom made brackets are used to hold the Arduino microcontroller and IR sensors to the Ebot chassis. After all the connections are in place, students develop a basic program to drive the Ebot forward for few seconds then backward for few seconds. The next step is to connect two IR sensors to the analog inputs of the Arduino microcontroller and read the sensor values. Students experimentally determine a threshold value at which the IR sensors can differentiate between black and white. Students develop a program for the Arduino microcontroller that incorporates the threshold values of the two IR sensors to control the Ebot motors. The goal is to create an Ebot that can 


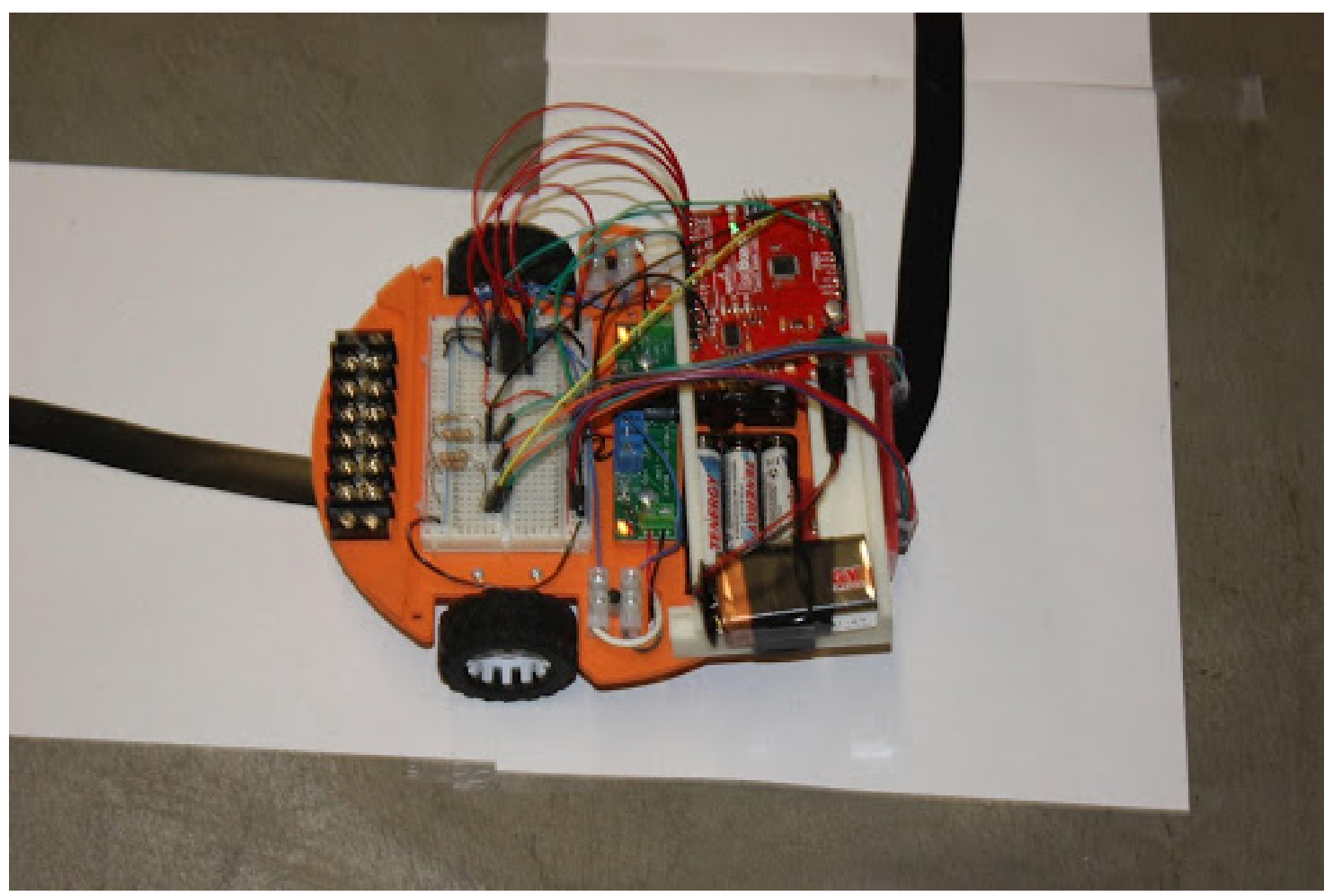

Figure 6: An autonomous Ebot following a black line

autonomously follow a black line. The controller shell and tether wire are no longer used.

\section{Week 7}

Student teams race their autonomous line following Ebots on a small course consisting of a black line on a white background, Fig. 6. Ebots are timed as they follow the black line from the start of the course until they stop at the end. The objective of this competition is to demonstrate a system level application where electronics, sensing, and computing are combined. There are no penalties for mistakes during the competition. Each team receives bonus points based on how successfully and quickly their Ebot navigates and completes the course.

\section{Student Survey}

In the Fall 2018 semester, fifty-six students were anonymously surveyed upon completion of the EPADS ECE module. The survey asked students their opinions and attitudes towards the module with twelve items having response options on a five-point Likert scale and five short open-ended questions.

After analyzing the survey data, it indicates the following results on the overall ECE module:

- $89 \%$ of the students agreed or strongly agreed that they had learned a great deal in this module 
- $78 \%$ of the students agreed or strongly agreed that the module provided them with an understanding of electrical and computer engineering

- $91 \%$ agreed or strongly agreed the ECE module was fun

- $76 \%$ of the students felt the workload out of class was about right, and there was enough time in class for laboratory work

Students were also prompted to provide any additional feedback about the ECE module, "Please write any other comments or feedback here about the ECE module and/or the instructors" some responses included comments about the instructors. Some of those comments included:

- "Dr. X is a great instructor"

- "Thanks for a great 7 weeks Dr. X"

- "Dr. X was fun to be with"

- "Dr. X keep up the good work. I really enjoyed the class."

- "Dr. X is very invested in the students and really cared about what was happening in the class. I very much enjoyed this class."

Additional feedback was collected to assess if the "autonomous line follower" project was beneficial to a student's learning of introductory electrical and computer engineering concepts. Note that three of the surveyed students left this section of the survey blank. The results are summarized in Table 1.

Table 1: Student self-report feedback to the autonomous line follower project $(n=53)$

\begin{tabular}{|l||c|c|c|c|c|}
\hline \multicolumn{1}{|c|}{ Survey Question } & $\begin{array}{c}\text { Strongly } \\
\text { Disagree }\end{array}$ & $\begin{array}{c}\text { Disagree } \\
\text { Somewhat }\end{array}$ & Neutral & $\begin{array}{c}\text { Agree } \\
\text { Somewhat }\end{array}$ & $\begin{array}{c}\text { Strongly } \\
\text { Agree }\end{array}$ \\
\hline \hline $\begin{array}{l}\text { I learned some basic } \\
\text { electronics integration } \\
\text { skills with this project. }\end{array}$ & $0 \%$ & $3.77 \%$ & $5.66 \%$ & $35.85 \%$ & $\mathbf{5 4 . 7 2 \%}$ \\
\hline $\begin{array}{l}\text { I learned some basic pro- } \\
\text { gramming skills with this } \\
\text { project. }\end{array}$ & $1.89 \%$ & $7.55 \%$ & $11.32 \%$ & $37.74 \%$ & $\mathbf{4 1 . 5 1 \%}$ \\
\hline $\begin{array}{l}\text { Doing this project helped } \\
\text { me better understand the } \\
\text { practical uses of elec- } \\
\text { tronics. }\end{array}$ & $1.89 \%$ & $3.77 \%$ & $3.77 \%$ & $\mathbf{5 0 . 9 4 \%}$ & $39.62 \%$ \\
\hline $\begin{array}{l}\text { My teamwork skills } \\
\text { and confidence have } \\
\text { improved. }\end{array}$ & $1.89 \%$ & $3.77 \%$ & $18.87 \%$ & $\mathbf{3 9 . 6 2 \%}$ & $35.85 \%$ \\
\hline
\end{tabular}

When students were asked "what they liked about this module" the top comment was the 
hands-on learning. Other recurring comments included constructing the Ebot, rewiring the Ebot each class, and the introduction to programming. Although many students expressed a positive interest in programming, other students commented that it was one of the things "they did not like about the ECE module." Students also reported that they found parts of the ECE module to be confusing as the material was not explained clearly.

"Programming" or "coding" was also the most common answer given in the open-ended question, "What do you wish the ECE module would have covered but did not?"

Overall, the majority of the students had positive comments about their experiences during this module. Some of those students comments included:

- "Robotics was a great choice for the project"

- "The class material was fun and had a good amount of quizzes"

- "Such a great feeling when bot works properly"

- "Fun to be able to change your code to make each cart work"

- "I liked being able to see the results of my work come to life"

- "I think the class helped prepare me for future engineering classes and I really enjoyed it"

The students' comments and survey results were consistent with the observations of the authors.

\section{Assessment and Evaluation}

Student work was assessed on the following categories based on the instructor's direct observation.

System integration: On most class days each team completed an integration task, such as the successful inclusion of 1) simple SPST and SPDT switches with the Ebot handheld controller to reverse motor direction and 2) potentiometers and an operational amplifier to vary motor speed. During the final three weeks students integrate optical sensors and an Arduino ${ }^{\mathrm{TM}}$ microcontroller with the Ebot platform to navigate autonomously a winding black line. Observations made by the instructors indicate that $40 \%$ of the teams completed the integration tasks on time with little to no help, $30 \%$ of the teams required some help and the remaining $30 \%$ required substantial help from the instructors. This system integration exercise is an early introduction to the ABET student outcome 2, "an ability to apply engineering design to produce solutions that meet specified needs with consideration of public health, safety, and welfare, as well as global, cultural, social, environmental, and economic factors" [1].

Teamwork: Students work in pairs often comprised of students from two different engineering majors. This mix of majors is an early effort to facilitate their ability to function effectively on multidisciplinary teams. The student survey indicates that more than $75 \%$ of students felt that the experience improved their teamwork skills and confidence. These results support the program requirement to assess ABET student outcome 5, "an ability to function effectively on a team 
whose members together provide leadership, create a collaborative and inclusive environment, establish goals, plan tasks, and meet objectives" [1].

Communication: Our engineering programs foster communication skills through project-based learning experiences in the fall freshman year and throughout the curriculum. The relatively small class sizes at York College of Pennsylvania allow the instructors to closely observe and assist students in their efforts to communicate and work with other students in class and to monitor communications between students on one or more online learning management systems. At the end of the Ebot module students report an increase in comfort and ability to share ideas with others. This assessment addresses ABET student outcome 3, "an ability to communicate effectively with a range of audiences" [1].

Overall: The primary goals of this EPADS course, including both the ECE and the MCE modules, are to (i) give students an appreciation for the design process, especially the role of design parameters and constraints, the dynamics of group work, and the importance of effective peer-to-peer communication, (ii) provide basic skills and insights related to electronic design, and (iii) introduce students to CAD and machining techniques. The ECE module is directly related to course goals (i) and (ii). During the design activities students practiced and improved communication skills among peers and with the instructor. Students were exposed to specifications and constraints, such as those relevant to sensor and motor performance, and were asked to take into account variables such as battery life and ambient lighting.

\section{Conclusions}

The EPADS course was designed to introduce freshman engineering students to the engineering disciplines and the skills required by those disciplines. The seven-week ECE module focuses on engineering design, communication, and teamwork through a sequence of activities in which the students work in pairs to gradually build up an autonomous line following robot. Student surveys and instructor observations show that EPADS has been successful in providing students insight into the engineering disciplines, developing their communication skills, and improving their self-confidence. It is important to add that an overarching goal of the EPADS course is to create within each student a sense of affiliation with the engineering school. It is our belief that student retention and success is tightly correlated with a sense of belonging, between student peers and between students and their program. By bringing full-time faculty into close and persistent contact with students in the fall freshman year and throughout the curriculum, the engineering programs at York College of Pennsylvania hope to create an environment where students feel supported and encouraged to survive the significant challenges of an undergraduate engineering education. 


\section{References}

[1] ABET, “Criteria for Accrediting Engineering Programs, 2019 - 2020,” ABET, 2018.

[2] V. Ercolano, "From Sleep to 101 to Success 101," ASEE Prism, pp. 24-29, September 1995.

[3] V. Ercolano, "Designing Freshman," ASEE Prism, pp. 20-25, April 1996.

[4] S. Sheppard and R. Jenison, "Examples of Freshman Design Education," International Journal of Engineering Education, vol. 13, no. 4, pp. 248-261, 1997.

[5] L. E. Carlson and J. F. Sullivan, "Hands-on Engineering: Learning by Doing in the Integrated Teaching and Learning Program," International Journal of Engineering Education, vol. 15, no. 1, pp. 20-31, 1999.

[6] E. Wang, N. Velasquez-Bryant, J. Adams, T. Batchman, P. Cantrell, E. Jacobson, W. Johnson, J. Kleppe, J. LaCombe, N. LaTourrette, G. Norris, W. Sparkman, and Y. Varol, "First Year Engineering Experience Initiative," in ASEE Annual Conference and Exposition, Salt Lake City, UT, 2004.

[7] L. Prendergast and E. Etkina, "Review of a First-Year Engineering Design Course," in ASEE Annual Conference and Exposition, Indianapolis, IN, 2014.

[8] J. Ray and J. Farris, "First-Year Engineering Product Realization," in ASEE Annual Conference and Exposition, St. Louis, MO, 2000.

[9] M. F. Bays-Muchmore and A. Chronopoulou, "First Year Engineering Students Perceptions of Engineering," in ASEE Annual Conference and Exposition, Salt Lake CIty, UT, 2018.

[10] K. Meyers, J. Uhran, C. Pieronek, D. Budny, J. Ventura, P. Ralston, J. K. Estell, B. Hart, C. Slaboch, and R. Ladewski, "Some Perspectives on First Year Engineering Education," in ASEE Annual Conference and Exposition, Pittsburgh, PA, 2008. 